\title{
Study of the density of horns from cervids
}

\author{
Yury Evgenjevich Vashukevich ${ }^{1, *}$, Elena Valirievna Vashukevich ${ }^{1}$, Gottlieb Polzer ${ }^{1}$, \\ Liza Polzer $^{1}$, Svetlana Viktorovna Shvetsova ${ }^{1}$ and Victoria Mikhailovna Khantakova ${ }^{2}$ \\ ${ }^{1}$ Irkutsk State Academy of Agriculture, Irkutsk, Russia \\ ${ }^{2}$ Eurasian Linguistic Institute of Moscow State Linguistic University, Irkutsk, Russia \\ *Correspondent: rector1@igsha.ru
}

\begin{abstract}
The article is devoted to the study of the density dependence of the horns tissue on the species and the age of the representatives of the deer family. In scientific literature this problem was covered partially. Basic physical parameters (mass, volume, and density) of horns from red deer (Cervus elaphus), fallow deer (Dama dama), European (Capreolus capreolus) and Siberian roe deer (Capreolus pygargus) were estimated. The present study was designed to analyze the results for making identification of species and age of the animal possible.
\end{abstract}

Keywords: cervids (Cervidae), density of horns, density on deer age, dependence of mass, dry shed horns, volume

\section{INTRODUCTION}

Deer horns are indicators of their physiological state. In practical hunting it is possible to define: species (subspecies), population of the animal, sex, harvesting season, nutrition and health state of the individual by the shape and size of the horns (or their absence). Horns also serve for visual identification of the deer age. But as a rule, the age can be determined only approximately, since adult males of red deer for several (5-7) years have horns similar in shape, weight, and volume. Many morphological, physical, and mechanical properties of horns are profoundly analyzed. But in scientific literature there is little data on the studies on the density of the horns in different periods of animals' life.

The authors suggested that over the years in male deer they observed changes not only in shape and volume of horns tissue but in the density too. It may serve as an additional means to estimate the age of animal. In addition, the density of the horns in various species of deer is different. It may be recognized as a criterion for species identification of horns fragments.

Partially this hypothesis was confirmed in the article.

\section{Materials ANd Methods}

The research was conducted using the horns from the private collection of Professor Gottlieb Polzer (Schonfeld, Germany) in the period January-September, 2014. Mass of dry horns was measured on the electronic scale accurate to $1 \mathrm{gram}$. The volume of horns was estimated with measuring container filled with water, with 10 milliliters graduation scale. The density of horns was estimated according to the formula $\mathrm{q}=\mathrm{m} / \mathrm{V}$ (Paramio et al., 2012). The age of animals was determined by expertise and on the grounds of specialists' opinions. We used in our study 9 research papers (Miller et al., 1985; Smirnova, 1989; Danilkin, 1998; Lihatskiy and Kolomeitsev, 2002; Stepanova, 2002; Smirnov, 2007; Landete-Castillejos et al., 2009; Teplyashin and Drozdova, 2012) as principal bibliographical sources.

We used 100 shed dry horns from red deer, fallow deer, European and Siberian roe deer for research (Table 1). The identification of horns species was conducted by Professor Gottlieb Polzer and Yu. Vashukevich. The calculation of statistics was done using the program Micro-

Table 1. The quantity of carried out measurements.

\begin{tabular}{lcc}
\hline Animal species & $\begin{array}{c}\text { Samples of paired horns, } \\
\text { pairs/horns }\end{array}$ & $\begin{array}{c}\text { Individual } \\
\text { horns, pcs. }\end{array}$ \\
\hline Fallow deer & $8 / 16$ & 7 \\
Red deer & $16 / 32$ & - \\
European roe deer & - & 36 \\
Siberian roe deer & - & 9 \\
Total & $24 / 48$ & 52 \\
\hline
\end{tabular}


soft Office 2007.

\section{Results}

The research found the density of shed horns from male deer increases progressively until six years (the correlation index is $R^{2}-0.79$, the density is from 1.0 to 1.39 $\left.\Gamma / \mathrm{cm}^{3}\right)$. In the age from 7 to 12 years old the density of horns did not change and had the tendency to decrease to $1.25 \mathrm{~g} / \mathrm{cm}^{3}$ to the age of 12 years.

The density of horns tissue in males of fallow deer also increases until 4 years (the correlation index is 0.69 , the density is from 0.5 to $1.36 \mathrm{~g} / \mathrm{cm}^{3}$ ).

The average density in different deer species is presented in the following values:

Red deer $-1.28 \mathrm{~g} / \mathrm{cm}^{3}$

Fallow deer $-0.98 \mathrm{~g} / \mathrm{cm}^{3}$

European roe deer $-1.49 \mathrm{~g} / \mathrm{cm}^{3}$

Siberian roe deer $-1.58 \mathrm{~g} / \mathrm{cm}^{3}$

It may be assumed that the density data obtained in the assessments of horns or their fragments may serve as an additional criterion to identify the species and the age of an animal.

\section{Discussion}

The ossified horns of wild ungulates, from the point of view of hunting, perform several different functions.

First, the horns are indicators of the health state in the living species of game animals. By their shape, degree of development, size, color, and others parameters wildlife managers make the decision whether to use deer in breeding or in trophy hunting.

Secondly, it is a valuable raw material for folk medi- cine, pharmaceutical industry, and production of various decorative items.

The analysis of the literature [1-9] showed a wide range of research on study and detection of the various qualities and characteristics of horns from cervids. These works relate to ecological, morphological, chemical, physical, mechanical, and other properties of the horns. However, we could not find classified material on density of horns tissue in deer in the studied articles of national and foreign authors. It is submitted that the density of the horns can be useful for determining the age and species of animals, as well as to assess the state of the feeding balance in the diet of deer in a given population. In the practical work experts-biologists face the need to accurately assess the animal species by separate horns or by their fragments. In this situation it is useful to add physical characteristics, such as the density of the horns tissue to organoleptic and chemical methods of assessment. Our studies have been conducted to solve this practical problem.

One hundred dry ossified shed horns of four species: red deer, fallow deer, European and Siberian roe deer were taken as the experimental material. Professor Gottlieb (Schonfeld, Germany) provided the horns from his private collection. Theoretically, the most reliable results of the dynamics of density can be obtained from horns of one and the same animal in the course of a lifetime, regularly and timely gathering his shed derivatives. The collection of such material in the wild is very difficult and often it is impossible. Deer shed horns in various inaccessible and remote areas. These horns and are quickly destroyed by rodents and other animals.

For this reason, for our research we have taken horns from one and the same male deer out of Hirschfeld Wildlife Park (Germany). The horns had been collected for twelve years.

The main values of measurements are represented in

Table 2. Indicators of mass, volume and density of the horns of a male deer in Hirschfeld Wildlife Park, Germany.

\begin{tabular}{|c|c|c|c|c|c|c|c|c|c|}
\hline \multirow{2}{*}{ Age, yrs } & \multicolumn{3}{|c|}{ Mass, $\mathrm{g}$} & \multicolumn{3}{|c|}{ Volume, $\mathrm{cm}^{3}$} & \multicolumn{3}{|c|}{ Density $\mathrm{g} / \mathrm{cm}^{3}$} \\
\hline & Left & Right & $\mu$ & Left & Right & $\mu$ & Left & Right & $\mu$ \\
\hline 1 & 180 & 180 & 180 & 180 & 180 & 180 & 1.00 & 1.00 & 1.00 \\
\hline 2 & 1100 & 1160 & 1130 & 840 & 920 & 880 & 1.31 & 1.26 & 1.29 \\
\hline 3 & 1680 & 1840 & 1760 & 1350 & 1240 & 1295 & 1.24 & 1.48 & 1.36 \\
\hline 4 & 1420 & 1580 & 1500 & 1010 & 1170 & 1090 & 1.41 & 1.35 & 1.38 \\
\hline 5 & 2060 & 1920 & 1990 & 1450 & 1430 & 1440 & 1.42 & 1.34 & 1.38 \\
\hline 6 & 2100 & 2120 & 2110 & 1500 & 1550 & 1525 & 1.4 & 1.37 & 1.39 \\
\hline 7 & 2380 & 2460 & 2420 & 1850 & 1950 & 1900 & 1.29 & 1.26 & 1.28 \\
\hline 8 & 2470 & 2540 & 2505 & 1950 & 2050 & 2000 & 1.27 & 1.24 & 1.26 \\
\hline 9 & 2600 & 2700 & 2650 & 1950 & 1950 & 1950 & 1.33 & 1.38 & 1.36 \\
\hline 10 & 2560 & 2750 & 2655 & 1900 & 2000 & 1950 & 1.35 & 1.38 & 1.37 \\
\hline 11 & 2220 & 2420 & 2320 & 1850 & 2000 & 1925 & 1.2 & 1.21 & 1.21 \\
\hline 12 & 2200 & 2760 & 2480 & 1650 & 2350 & 2000 & 1.33 & 1.17 & 1.25 \\
\hline
\end{tabular}

$\mu$ - average mean 
Table 2.

As it can be seen, until the age of six (full maturation of the horns) the horns tissue density had been gradually growing in the range from 1.00 to $1.39 \mathrm{~g} / \mathrm{cm}^{3}$. Schedule of changes in mass, volume, and density of the deer horns in this period is shown in Fig. 1.

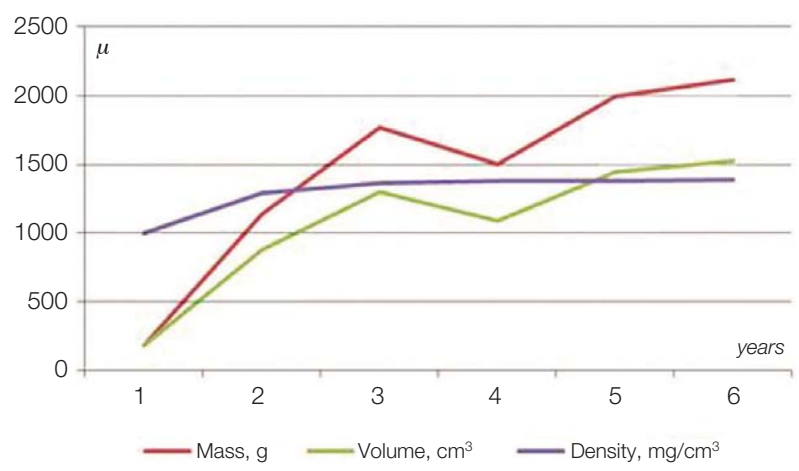

Fig. 1. The curves of changes of mass, volume and density of the horns of the male red deer at the age from 1 year to 6 years of age (inclusively).
Despite the fact that the mass and volume of the horns continued to grow until the age of twelve, the increase in the density of the horns during the period from 7 to 12 years did not occur (Fig. 2). At 11-12 years of age the values of horns tissue density became below $1.3 \mathrm{~g} / \mathrm{cm}^{3}$.

A summary graph of the dependence of considered

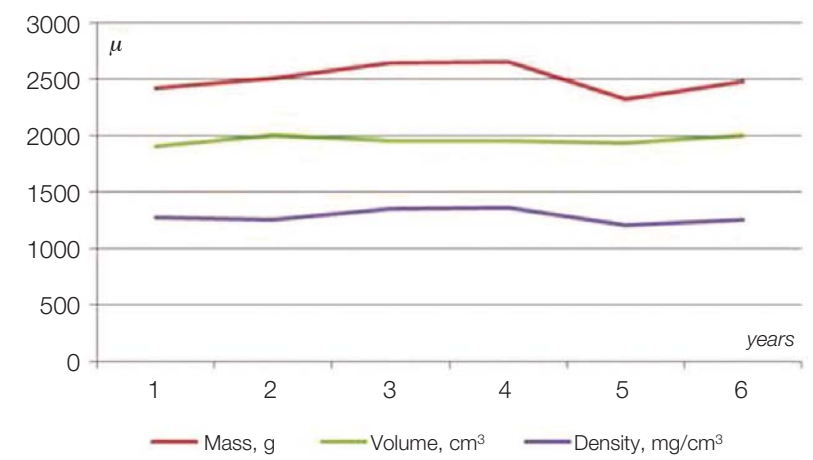

Fig. 2. The curves of changes of mass, volume and density of the horns of the male red deer at the age from 7 years to 12 years of age (inclusively).

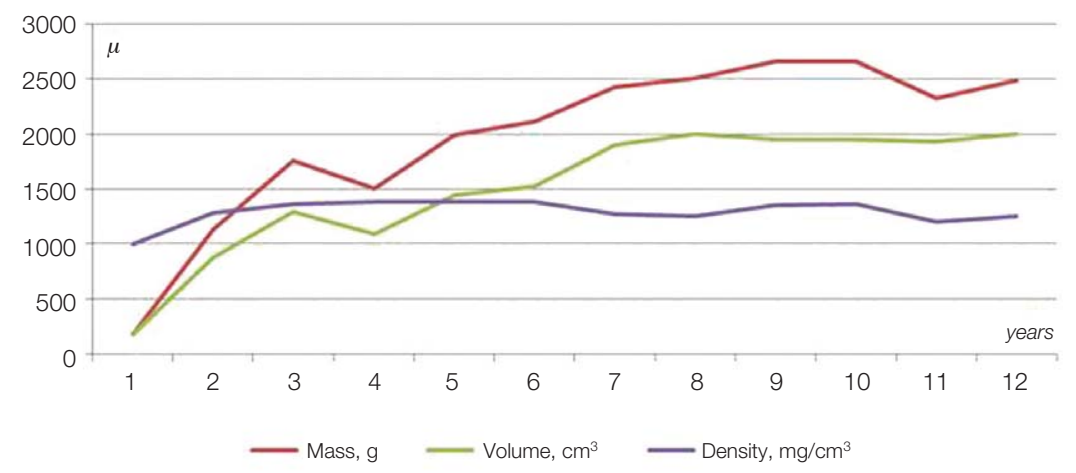

Fig. 3. The curves of changes of mass, volume and density of the horns of the male red deer at the age from 1 year to 12 years of age (inclusively).

Table 3. Density of horns tissue in fallow deer.

\begin{tabular}{|c|c|c|c|c|c|c|c|c|c|}
\hline \multirow{2}{*}{ Age, yrs } & \multicolumn{3}{|c|}{ Mass, $\mathrm{g}$} & \multicolumn{3}{|c|}{ Volume, $\mathrm{cm}^{3}$} & \multicolumn{3}{|c|}{ Density $\mathrm{g} / \mathrm{cm}^{3}$} \\
\hline & Left & Right & $\mu$ & Left & Right & $\mu$ & Left & Right & $\mu$ \\
\hline \multirow[t]{2}{*}{1} & 50 & 47 & 48.5 & 100 & 80 & 90 & 0.50 & 0.59 & 0.55 \\
\hline & 48 & 56 & 52 & 90 & 100 & 95 & 0.53 & 0.56 & 0.55 \\
\hline$\mu$ & - & - & - & - & - & - & - & - & 0.55 \\
\hline \multirow[t]{2}{*}{2} & 380 & 95 & 237.5 & 280 & 130 & 205 & 1.36 & 0.73 & 1.05 \\
\hline & 610 & 620 & 615 & 575 & 510 & 542.5 & 1.06 & 1.22 & 1.14 \\
\hline$\mu$ & - & - & - & - & - & - & - & - & 1.09 \\
\hline \multirow[t]{4}{*}{3} & 860 & 800 & 830 & 740 & 650 & 695 & 1.16 & 1.23 & 1.20 \\
\hline & 1040 & 1240 & 1140 & 960 & 1225 & 1092.5 & 1.08 & 1.01 & 1.05 \\
\hline & - & 1100 & 1100 & - & 940 & 940 & - & 1.17 & 1.17 \\
\hline & - & 1080 & 1080 & - & 880 & 880 & - & 1.23 & 1.23 \\
\hline$\mu$ & - & - & - & - & - & - & - & - & 1.16 \\
\hline 4 & 880 & 960 & 920 & 840 & 975 & 907.5 & 1.05 & 0.98 & 1.02 \\
\hline
\end{tabular}

$\mu$ - average mean 
values of deer age is represented in Fig. 3.

It is important to note that the correlation coefficients in the first age phase (1-6 years) between age and weight (0.90) and age and volume (0.88) are higher than the coefficient which characterizes the dependence between age and density of the horns tissue (0.79).

In the second age phase (7-12 years) dependence of density on the age and volume is not assessed. Dependence on weight was: found as $R^{2}=0.94$.

The density values of fallow deer horns tissue from the area Lichtentanne (Germany) are represented in Table 3.

The table shows that the density of deer horns is also growing until the age of horns maturity (4 years) in males. The relationship between the age of the deer and the density of his horns tissues exists, the correlation coefficient is 0.69 .

Calculations of the average density of studied horns showed that this value is distinguished in all four species and it may be used for identification of taxon.

\section{CONCLusion}

According to the research results the following principal conclusions can be stated:

1. It is necessary to continue research on tissue density of shed deer horns, as one of the indexes of the state of the deer population on the local territory.

2. The density indexes of horns depend on the age of deer. In the first phase of animal life the density of horns increases to complete horns maturation. In the second phase the increase in weight and volume of horns continues but the increase of density terminates.

3 . The density values of horns in different animal species distinguish. The most solid horns from the tested samples are in roe deer. The lowest density of horn tissue was found in males of fallow deer.

\section{REFERENCES}

Danilkin, A.A. 1998. Cervids. GEOS, Moscow (in Russian).

Landete-Castillejos, T., L. Gallego, A. Garcia and J. Estevez, 2009. The characterization of the population of deer based on the composition of horns. Hunting: national hunting magazine, Moscow, 11:20-25 (in Russian).

Lihatskiy, Yu.P. and S.G. Kolomeitsev. 2002. The excrescence and development of European red deer horns from the mother and filial populations. Voronezh. pp. 66-69 (in Russian).

Miller, K.V., R.L. Marchinton, J.R. Beckwith and P.B. Bush. 1985. Variations in density and chemical compositions of white-tailed deer antlers. J. Mamm., 66(4):693-701 (in English).

Paramio, M.A.R., J. Muñoz-Cobo, J. Moro, R. Gutierrez, A. Oya, S. Tellado and C. Azorit. 2012. Assessing red deer antler density with a hydrostatic method versus a new parametric volume-modelling technique using 3D-CAD [Available from: http://dx.doi.org/10.1071/AN12015, accessed July 20, 2012 (in English)].

Smirnov, M.N. 2007. Red deer in the South Siberia. SFU, Krasnoyarsk (in Russian).

Smirnova, M.N. 1989. Wild ungulates in the South of Siberia (the historical changes of the population, the problem of use). Management of wild ungulates populations. Kirov. pp. 59-75 (in Russian).

Stepanova, V.V. 2013. Morphological peculiarities of red deer horns in Yakutia (Cervus elaphus) [Available from: http://www.zoology.dp.ua/z_09_209.html, accessed May 25, 2013 (in English)].

Teplyashin, V.N. and N.A. Drozdova. 2012. The measurement of physical and mathematical properties of antlers and horns of domestic reindeer of Evenki breed. J. Vestnik. Krasnoayrsk. pp. 192-196(in Russian).

Submitted: November 2, 2014

Revised: February 13, 2015

Accepted: February 25, 2015 